\title{
ALOKASI WAKTU KERJ A \\ PETANI HORTIKULTURA PINGGIRAN KOTA \\ (Studi Kasus di Kelurahan Sumberjaya, Kota Pematangsiantar)
}

\author{
J ef Rudiantho Saragih
}

\begin{abstract}
ABST RACT
The farmers's household by naturally will effort to enhance their income from farm-gate activity. The aim of this research is: (1) studying of time alocation of horticalture farmer which use to main activity (horticulture) and side activity (livestock, fishpond, small shop, or farmhand); (2) analyzing of labor productivity that determined by return to labor. Based on time alocation, income from main activity is comparing with income from combination of activity (main plus side activity). To test the difference between that income (main vs combination of activity), use t-test (paired comparison). Research was took place on J une to August 2006. In the Pematangsiontor suburban, land-owner per household generaly is very limited (average 0,15 hectare). The result of the research point out that combination of activity that give biggest income is horticulture plus small shop. However, from the productivity side, horticulture plus fishpond is resulting highest productivity of labor. Although horticulture farmer's family have done main and side activity, 44 percent (about 169 hours per three month) work time still idle yet (underemployment). So, the result of this research can suggest to enhanching the scale of activity, mainly livestock and/ or fishpond. A part from that, local government and other institutions can introduce others activities, such as small and household industry.
\end{abstract}

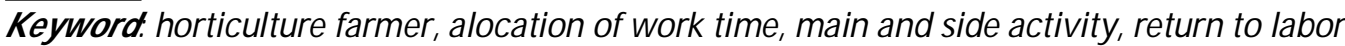

\section{PENDAHULUAN}

Secara alamiah, setiap rumah tangga akan berusaha memenuhi kebutuhan minimumnya dan senantiasa ingin meningkatkan taraf hidupnya. Untuk mencapai tujuan tersebut, rumah tangga berusaha untuk memperoleh pendapatan. Pendapatan yang diterima merupakan alat untuk mewujudkan kesejahteraan rumah tangga. Bagaimana rumah tangga memperoleh tingkat pendapatan tertentu ditentukan oleh bagaimana rumah tangga tersebut menggunakan/ mengalokasikan tenaga kerja yang tersedia dalam rumah tangga.

Studi mengenai ekonomi rumah tangga banyak yapg didasarkan pada teori yang dikembangkan oleh Becker (1976). Teori ini melihat rumah tangga sebagai produsen sekaligus sebagai konsumen. Sebagai produsen, rumah tangga bertujuan memaksimumkan keuntungan/ pendapatan dari kegiatan produktif yang dilakukan. Sebagai konsumen, rumah tangga bertujuan memaksimumkan kepuasan/ kesejahteraan dari barang dan jasa yang dikonsumsi, berdasarkan pendapatan yang tersedia.

Sumberdaya utama yang dimiliki oleh rumah tangga di negara-negara sedang berkembang, termasuk Indonesia, adalah tenaga kerja rumah tangga. Tenaga kerja sebagai faktor produksi tidak terlepas dari aspek sumberdaya manusia, dimana setiap rumah tangga memiliki strategi untuk mengalokaskan tenaga kerja yang ada untuk mengoptimalkan pendapatan, dan pada gilirannya memaksimumkan kepuasan rumah tangga.

Usaha produktif utama bagi petani adalah usahatani. Berbagai penelitian sudah dilakukan dan beberapa diantaranya menyimpulkan bahwa luas lahan merupakan 
salah satu faktor yang mempengaruhi penggunaan tenaga kerja. Terdapat kecenderungan bahwa luas pemilikan lahan berkaitan dengan jenis kegiatan produktif yang dilakukan.

\section{Tinjauan Teoritis dan Empiris}

Teori ekonomi rumah tangga tradisionil mengasumsikan bahwa setiap rumah tangga akan memaksimumkan kepuasan dari barang dan jasa yang dikonsumsinya. Fungsi kepuasan rumah tangga adalah:

$$
U=u\left(x_{1}, x_{2}, x_{3}, \ldots, x_{n}\right)
$$

dimana: $U$ adalah kepuasan total, dan $x_{i}$ adalah barang ke-i yang dikonsumsi. Untuk memaksimumkan kepuasan tersebut, rumah tangga dihadapkan pada kendala pendapatan untuk membeli barang dan jasa yang akan dikonsumsi, dengan persamaan:

$$
\sum P_{i} x_{i}=I=E+V
$$

dimana: $\mathrm{Pi}$ adalah harga barang $k e-i, x_{i}$ adalah jumlah barang ke-i, $\mathbf{I}$ adalah pendapatan total, $\mathrm{E}$ adalah pendapatan dari usaha produktif dan $\mathrm{V}$ adalah pendapatan lain.

Teori ekonomi rumah tangga yang dikembangkan oleh Becker (1976) memandang rumah tangga sebagai produsen sekaligus konsumen. Fungsi kepuasan/ kesejahteraan rumah tangga adalah sebagai berikut:

$$
\mathrm{U}=\mathrm{u}\left(\mathrm{Z}_{\mathrm{i}}\right)
$$

dimana $Z_{i}$ adalah komoditas yang dihasilkan rurnah tangga. Untuk memaksimumkan kepuasan tersebut, rumah tangga dibatasi oleh kendala produksi, waktu, dan pendapatan/ modal. Fungsi produksinya:

$$
Z_{i}=f\left(X_{i}, T_{i}\right)
$$

dimana: $\mathrm{X}_{\mathrm{i}}$ adalah pendapatan/ modal, dan $\mathrm{T}_{\mathrm{i}}$ adalah waktu.

Dalam memaksimumkan kesejahteraannya, rumah tangga menghadapi kendala pendapatan untuk membeli barang dan jasa, dengan persamaan:

$$
\sum P_{i} x_{i}=Y+\sum W_{j} T_{j}
$$

dimana:

$\mathrm{Pi}=$ harga barang $\mathrm{x}$ ke- $\mathrm{i}$

$\mathrm{xi}=$ barang dan jasa $\mathrm{x}$ yang dibeli di pasar

$Y=$ pendapatan lain

$W j$ = tingkat upah

$\mathrm{Tj}=$ jumlah wakru yang dialokasikan untuk bekerja

Waktu total yang dimiliki oleh tenaga kerja dalam rumah tangga adalah tetap, sehingga waktu juga merupakan kendala. Fungsi kendala waktu adalah: 


$$
T_{j}=T_{b}+T_{r t}+T_{1}
$$

dimana:

$\mathrm{T}_{\mathrm{j}}=$ waktu total yang dimiliki anggota rumah tangga

$\mathrm{T}_{\mathrm{b}}=$ waktu untuk bekerja

$T_{\text {rt }}=$ waktu untuk pekerjaan rumah tangga

$\mathrm{T}_{1}=$ waktu luang

Tenaga kerja rumah tangga merupakan input produksi yang sangat penting bagi petani. Petani pada umumnya kurang memiliki barang modal (capital good scarcity) dan kurang memperoleh informasi dan teknologi. Satu-satunya sumberdaya yang dimiliki petani pada umumnya adalah tenaga kerja rumah tangga. Bagaimana strategi menggunakan tenaga kerja rumah tangga untuk berbagai usaha merupakan aspek yang sangat penting karena alokasi tenaga kerja tersebut akan menggenerate pendapatan total petani dari berbagai usaha yang dilakukannnya.

Urgensi analisis alokasi tenaga kerja ini adalah karena (Anwar, 1997) petani di daerah tropis, seperti umumnya wilayah Indonesia, mengelola sumberdaya yang dimiliki secara lebih holistik sebagai suatu sistem yang terpadu, tidak sebagai komponen-komponen yang terpisah. Dengan demikian, jumlah tenaga kerja yang dialokasikan oleh petani untuk berbegai jenis usaha diasumsikan sebagai alokasi yang mampu memberikan tingkat pendapatan total optimum bagi rumah tangga.

\section{Tujuan Penelitian}

Penelitian bertujuan untuk (1) mengetahui alokasi waktu kerja produktif dan pendapatan petani berlahan sempit di pinggiran Kota Pematangsiantar, yang digunakan untuk usahatani (usaha utama) dan usaha sampingan; dan (2) untuk mengetahui kombinasi usaha utama dan usaha sampingan yang lebih besar menyumbang pendapatan keluarga petani.

\section{METODE PENELITIAN}

Penelitian dilakukan di Kelurahan Sumberjaya Kecamatan Siantar Martoba, Kota Pematangsiantar pada bulan J uni s.d. Agustus 2006. Responden penelitian adalah petani hortikultura, yang melakukan usaha produktif sampingan/tambahan; yaitu: usaha ternak, kolam, warung, dan buruh tani. Responden diambil secara sengaja (purposive) dengan mempertimbangkan kombinasi usaha hortikultura dan usaha tambahan (Tabel 1).

Tabel I. J umlah Responden Penelitian untuk masing-masing Kombinasi Usaha

\begin{tabular}{clcc}
\hline No. & Kombinasi Usaha Produktif & $\begin{array}{c}\text { Jumlah Responden } \\
\text { (KK) }\end{array}$ & $\begin{array}{c}\text { Luas Lahan Rata-rata } \\
\text { (ha) }\end{array}$ \\
\hline 1 & Hortikultura + Ternak & 7 & 0,15 \\
2 & Hortikultura + Kolam & 8 & 0,17 \\
3 & Hortikultura + Warung & 5 & 0,16 \\
4 & Hortikultura + Buruhtani & 5 & 0,11 \\
& Rata-rata & & 0,15 \\
\hline
\end{tabular}




\section{Metode Pengolahan Data}

Untuk melihat peran usaha tambahan terhadap pendapatan total rumah tanggq maka dilakukan komparasi antara pendapatan usaha hortikultura dengan pendapatan kombinasi usaha (hortikultura dan usaha tambahan). Alat analisis yang digunakan adalah uji beda rata-rata dengan menggunakan uji-t, sebagai berikut (Huntsberger and Billingsley, 1973):

$$
\begin{gathered}
t_{h}=\frac{\bar{Y}_{k}-\bar{Y}_{h}}{s_{g}} \\
s_{g}=\sqrt{S^{2}\left(\frac{1}{n_{1}}-\frac{1}{n_{2}}\right)=\sqrt{\frac{2 S^{2}}{n}\left(n_{1}=n_{2}\right)}} \\
S^{2}=\frac{\sum\left(Y_{k i}-\bar{Y}_{h}\right)^{2}+\sum\left(Y_{h j}-\bar{Y}_{h}\right)^{2}}{n_{1}+n_{2}-2}
\end{gathered}
$$

dimana:

$t_{\mathrm{h}}=$ nilai $\mathrm{t}$ (t-hitung)

$\mathrm{Y}_{\mathrm{k}}=$ pendapatan rata-rata kombinasi usaha (Rp)

$Y_{h}=$ pendapatan rata-rata usaha hortikuttura $(R p)$

$\mathrm{Y}_{\mathrm{ki}}=$ pendapatan kombinasi usaha responden ke-i (Rp)

$\mathrm{Y}_{\mathrm{kj}}=$ pendapatan usaha hortikultura responden ke-j (Rp)

$\mathrm{S}_{\mathrm{g}} \quad=$ simpangan baku gabungan

$\mathrm{S}^{2}=$ varian bersama

J ika th > t-tabel ( $\alpha=5 \%$; $d b=2 n-2$ ), maka usaha sampingan berkontribusi nyata terhadap pendapatan total rumah tangga.

Untuk mengetahui usaha yang lebih optimal menyumbang pendapatan rumah tangga dilakukan analisis return to labor (RTL) untuk usaha hortikultura, usaha tambahan, dan kombinasi usaha, sebagai berikut:

dimana:

$$
R T L=\frac{Y}{L}
$$

$\mathrm{RTL}=$ return to labor (produktivitas tenaga kerja), $\mathrm{Rp} / \mathrm{jam}$

$\mathrm{Y} \quad=$ pendapatan $(\mathrm{Rp})$

$\mathrm{L} \quad=$ alokasi tenaga kerja (jam)

\section{HASIL PENELITIAN DAN PEMBAHASAN}

\section{Penerimaan}

Untuk mengetahui tingkat pendapatan petani hortikultura terlebih dahulu dilihat struktur penerimaan usahatani dan usaha sampingan.

Tabel 2 di atas menunjukkan bahwa penerimaan paling besar diperoleh dari kombinasi usahatani hortikultura dan usaha ternak, disusul hortikultura dan kolam, hortikultura dan warung serta hortikultura dan buruhani. Usahatani hortikultura pada ke empat kombinasi usaha tersebut, dapat disimpulkan bahwa semakin besar luas usatratani maka penerimaan dari usaha tani semakin besm pula (bandingkan dengan 
Tabel I). Penerimaan yang besar pada kombinasi hortikultura dan ternak, sebagian besar merupakan sumbangan usaha sampingan sebesar 76 persen. Sementara itu, usaha sampingan warung memperoleh penerimaan tercndah, dan relatif kurang produktif karena menggunakan waktu yang relatif tinggi.

Tabel 2. Penerimaan Total (Rp) dari Usahatani Hortikultura dan U saha Sampingan per Tiga Bulan (satu MT Hortikultura)

\begin{tabular}{lccrc}
\hline Uraian & $\mathrm{H}+\mathrm{T}$ & $\mathrm{H}+\mathrm{K}$ & $\mathrm{H}+\mathrm{W}$ & $\mathrm{H}+\mathrm{B}$ \\
\hline Hortikultura & 1.758 .143 & 2.273 .500 & 2.039 .800 & 1.464 .625 \\
Sampingan & 5.531 .429 & 780.625 & 952.000 & 1.087 .500 \\
J umlah & 7.289 .572 & 3.054 .125 & 2.991 .800 & 2.552 .125 \\
\hline \multicolumn{4}{r}{ Keterangan: Disamping usahatani hortikultura (H), ada empat usaha sampingan: ternak (T), } \\
kolam (K), warung (W), dan buruhtani (B)
\end{tabular}

\section{Biaya}

Untuk mengetahui jumlah pendapatan (keuntungan) dari penerimaan tersebut, maka dihitung biaya produksi usahatani hortikultura maupun usaha sampingan. Biaya dimaksud adalah biaya faktor produksi, termasuk tenaga kerja sewa lahan, dan penyusutan alat (Tabel 3).

Tabel 3. Biaya Produksi (Rp) Usahatani Hortikultura dan Usaha Sampingan Per Musim Tanam Hortikultura (tiga bulan)

\begin{tabular}{llrrr}
\hline \multirow{2}{*}{ No. } & \multirow{2}{*}{ Kombinasi Usaha } & \multicolumn{2}{c}{ J umlah Biaya } & \multirow{2}{*}{ Biaya Total } \\
\cline { 3 - 4 } & & Hortikultura & \multicolumn{1}{c}{ Sampingan } & \\
\hline 1 & $\mathrm{H}+\mathrm{T}$ & 1.037 .286 & 5.191 .071 & 6.228 .357 \\
2 & $\mathrm{H}+\mathrm{K}$ & 1.149 .131 & 420.875 & 1.570 .000 \\
3 & $\mathrm{H}+\mathrm{W}$ & 1.122 .200 & 256.000 & 1.378 .200 \\
4 & $\mathrm{H}+\mathrm{B}$ & 750.000 & 362.500 & 1.112 .000 \\
\hline
\end{tabular}

Tabel 3 menunjukkan bahwa penerimaan yang tinggi pada kombinasi usaha hortikultura dan ternak pada Tabel 2, diperoleh dengan mengorbankan biaya yang besar pula. Biaya usaha sampingan ternak mencapai 83 persen dari biaya total pada kombinasi usaha ini. Dari sisi biaya, usaha sampingan ternak ini sangat tidak produktif. Usaha ternak ini hanya mampu memberikan penerimaan $\mathrm{Rp} 1,07$ dengan mengorbankan biaya Rp 1 (Revenue/ Cost, R/ C = 1,07). Sementara itu, R/ C untuk usaha sampingan lainnya adalah 1,85 untuk usaha kolam, 3,72 untuk usaha warung, dan 3,00 untuk kegiatan sebagai buruhtani. Dengan demikian, ukuran kinerja usahatani dan usaha sampingan yang paling akurat adalah pendapatan/ keuntungan dan produktivitas tenaga kerja.

\section{Pendapatan}

Pendapatan merupakan nilai produksi dari usahatani dikurangi biaya total dalam proses produksi selama satu kali musim tanam, ditambah pendapatan bersih dari usaha sampingan. 
Tabel 4. Pendapatan Rata-rata (Rp) Usahatani Hortikultura dan Usaha Sampingan Per M usim Tanam

\begin{tabular}{|c|c|c|c|c|c|c|c|}
\hline \multirow{2}{*}{ No } & \multirow{2}{*}{ Usaha } & \multicolumn{2}{|c|}{ Pendapatan } & \multirow{2}{*}{$\begin{array}{l}\text { Pendapatan } \\
\text { total }\end{array}$} & \multicolumn{3}{|c|}{ Uji beda rata-rata } \\
\hline & & Hortikultura & Sampingan & & $t_{h}$ & t. 05 & t. 01 \\
\hline 1 & $\mathrm{H}+\mathrm{T}$ & 720.857 & 340.357 & 1.061 .214 & 5,87 & 1,782 & 2,179 \\
\hline 2 & $\mathrm{H}+\mathrm{K}$ & 1.124 .369 & 359.750 & 1.484 .119 & 6,19 & 1,761 & 2,145 \\
\hline 3 & $\mathrm{H}+\mathrm{W}$ & 917.600 & 696.000 & 1.613 .600 & 10,39 & 1,860 & 2,306 \\
\hline 4 & $\mathrm{H}+\mathrm{B}$ & 714.125 & 725.000 & 1.439 .125 & 2,57 & 1,860 & 2,306 \\
\hline
\end{tabular}

Berbeda dengan penerimaan (tertinggi pada kombinasi hortikultura dan ternak), pada Tabel 4 dapat dilihat bahwa tingkat pendapatan total terbesar diperoleh dari kombinasi usaha hortikultura dan warung, disusul hortikultura dan kolam, hortikultura dan buruhtani, dan terkecil hortikultura dan temak. Usatra ternak ternyata memberikan pendapatan terkecil, meskipun mengorbankan modal dan biaya yang sangat besar.

Berdasarkan uji beda rata-rata yang membandingkan pendapatan usaha hortikultura dengan pendapatan total (hortikultura + sampingan), diperoleh kesimpulan bahwa semua usaha sampingan berkontribusi sangat nyata terhadap pendapatan total rumah tangga. Dengan kata lain, usaha sampingan yang dilakukan petani hortikultura di Kota Pematangsiantar (ternak, kolam, warung, dan buruhtani) mampu meningkatkan kesejahteraan petani dan dapat dipandang sebagai solusi terhadap keterbatasan lahan pertanian.

\section{Produktivitas Tenaga Kerja}

Untuk melihat usaha (usahatani atau usaha sampingan) yang paling produktif dalam menyumbang pendapatan rumah tangga, maka dilakukan perhitungan produktivitas tenaga kerja. Salah satu pendekatan yang dapat digunakan untuk mengukur produktivitas tenaga kerja (pertanian) adalah dengan menghitung return to labor (RTL), yaitu imbalan/pendapatan (bersih) yang diterima tenaga kerja per satuan alokasi waktu, dalam hal ini rupiah per jam (Tabel 5 dan 6).

Tabel 5. Alokasi Waktu untuk Usahatani Hortikultura dan Usaha Sampingan per Musim Tanam Hortikultura (jam/ 3 bulan)

\begin{tabular}{|c|c|c|c|c|c|c|}
\hline \multirow{2}{*}{ Uraian } & \multirow{2}{*}{ Tersedia } & \multicolumn{2}{|c|}{ Alokasi Tenaga Kerja } & \multirow{2}{*}{ - umlah $(H+S)$} & \multicolumn{2}{|c|}{ Sisa } \\
\hline & & $\mathrm{H}$ & $S$ & & $\mathrm{Jam}$ & $\%$ \\
\hline$\overline{\mathrm{H}+\mathrm{T}}$ & 396 & 154 & 42 & 196 & 200 & 50,51 \\
\hline $\mathrm{H}+\mathrm{K}$ & 378 & 168 & 28 & 196 & 182 & 48,15 \\
\hline $\mathrm{H}+\mathrm{W}$ & 385 & 168 & 9l & 259 & 126 & 32,73 \\
\hline $\mathrm{H}+\mathrm{B}$ & 385 & 112 & 105 & 217 & 168 & 43,64 \\
\hline Rerata & 386 & 151 & 67 & 217 & 159 & 43,76 \\
\hline
\end{tabular}

Keterangan: $\mathrm{H}=$ usahatani hortikultura, $\mathrm{S}=$ usaha sampingan [ternak $(\mathrm{T})$, kolam $(\mathrm{K})$, warung (W), dan buruhtani (B)]

Dari Tabel 5 dapat dilihat bahwa kombinasi usaha hortikultura dan warung menggunakan waktu yang paling tinggi, yaitu 259 jam; sementara produktivitas tenaga kerja bukanlah yang tertinggi. Alokasi waktu untuk usaha buruhtani merupakan yang tertinggr di antara usatra sampingan lainnya. Namun demikian, diri 
sisi produktivitas, tenaga kerja yang digunakan sebagai buruhtani merupakan yang terendatr. Tabel 5 juga memperlihatkan bahwa, setelah melakukan aktivitas usahatasi dan usaha sampingan, petani hortikultura di Pematangsiantar menyisakan rata-rata 169 jam (44 persen) waktu kerja yang masih menganggur (tidak produktif), dalam waktu tiga bulan. Dari sisi ekonomi, tingkat pengangguran (unemployment) angkatan kerja sektor pertanian hortikultura di daerah penelitian ini adalah sekitar 44 persen.

Tabel 6. Produktivitas Tenaga Kerja/ Return to Labor (Rp/ jam) Usaha Hortikultura dan U saha Sampingan

\begin{tabular}{ccccc}
\hline \multirow{2}{*}{ No } & \multirow{2}{*}{ Usaha } & \multicolumn{3}{c}{ Return to Labor } \\
\cline { 3 - 5 } & & Hortikultura & Sampingan & Gabungan \\
\hline 1 & $\mathrm{H}+\mathrm{T}$ & 4.681 & 8.104 & 5.414 \\
2 & $\mathrm{H}+\mathrm{K}$ & 6.693 & 12.848 & 7.572 \\
3 & $\mathrm{H}+\mathrm{W}$ & 5.462 & 7.648 & 6.230 \\
4 & $\mathrm{H}+\mathrm{B}$ & 6.376 & 6.905 & 5.632 \\
\hline
\end{tabular}

Berdasarkan perhitungan pendapatan (bersih) dibagi dengan alokasi waktu, maka diperoleh return to labor seperti dicantumkan pada Tabel 6 . Berdasarkan Tabel 6, dapat disimpulkan bahwa produktivitas tenaga kerja tertinggi dicapai pada kombinasi usaha hortikultura dan kolam (Rp 7.572/ jam), disusul hortikultura dan buruhtani, hortikultura dan warung, serta hortikultura dan ternak. Bila dibandingkan dengan return to labor yang setara upah minimum provinsi (UMP) Sumatera Utara (Rp $8.000 /$ jam), maka produktivitas tenaga kerja usahatani dan usaha sampingan pada Tabel 6 masih relatif lebih baik. Untuk itu, bila ada altematif usaha produktif lain untuk "mempekerjakan" waktu kerja yang belum digunakan (underemployment), maka pendapatan total dan kesejahteraan rumah tangga akan lebih meningkat.

\section{Implikasi Hasil Penelitian}

Sebagaimana diuraikan di atas, meskipun rumah tangga telah melakukan usaha sampingan, petani pinggiran kota pada penelitian ini masih memiliki waktu menganggur. Dengan menetapkan waktu bekerja sebesar 7 (tujuh) jam per hari, maka rata-rata 44 persen waktu kerja (169 jam) dalam 3 bulan belum digunakan. Kondisi keluarga tani tersebut, menurut Mubyarto (1989), termasuk ke dalam kategori underemployment, dimana di dalamnya termasuk pengangguran musiman. Dengan demikian, karena sifatnya underemployment, jika ada peningkatan skala usaha atau introduksi jenis usaha baru, maka waktu kerja yang menganggur tersebut dapat segera digunakan.

Dapatkah direkomendasikan agar petani hortikultura lebih meningkatkan usaha sampingan kolam atau ternak? Jawaban untuk pertanyaan tersebut adalah situasional. Berdasarkan pengamatan, usaha kolam masih dapat lebih diintensifkan sampai batas tertentu (terutama jumlah populasi ikan mas dan jumlah pakan yang diberikan). Upaya ekstensifikasi (perluasan kolam) hampir tidak dapat dilakukan, mengingat luas kolam dan pasokan air yang sangat terbatas.

Untuk usaha ternak, dari sisi ekonomi tidak disarankan untuk dikembangkan lebih lanjut, kecuali ada teknologi intensifikasi yang diperkenalkan. Namun karena aspekaspek sosial dan kultural sangat mendukung, usaha ternak (kambing) ini masih akan tetap berkembang.

Alternatif lain untuk memanfaatkan jam kerja yang menganggur, adalah mengintoduksi atau memperkenalkan usaha nonportanian skala kecil. Kegiatan yang 
dapat diperkenalkan adalah industri skala kecil berbahan baku hasil pertanian atau nonpertanian. Tahap awal perlu dilakukan identifikasi dan pembekalan petani melalui serangkaian pelatihan atau pemberdayaan. $\mathrm{Hal}$ ini tentu saja memerlukan kajian lebih lanjut agar relevan dengan kondisi dan kebutuhan petani.

\section{KESIMPULAN DAN SARAN}

\section{Kesimpulan}

1. Dalam meningkatkan pendapatannya, rumah tangga petani pinggiran kota mengalokasikan waktu kerja untuk usaha utama (usahatani hortikultura) dan memilih alternatif usaha sampingan (ternah, kolam, warung, dan buruhtani) yang diharapkan dapat menambah pendapatan rumah tangga. Pilihan usaha sampingan tersebut terutama dibatasi oleh kendala modal/ investasi awal.

2. Usaha produktif yang memberikan padapatan total tertinggi adalah kombinasi usaha utama (hortikultura) dan usaha sampingan warung. Namun bila dilihat dari sisi produktivitas tenaga kerja, dua usaha yang paling produktif dari ukuran return to labor, adalah kombinasi usaha hortikultura dengan usaha sampingan kolam dan buruh tani.

3. Setelah melakukan usaha sampingan, tenai hortikultura pinggiran kota masih memiliki waktu menganggur (di luar waktu mengerjakan pekerjaan rumah tangga dan waktu luang). Dengan waktu bekerja 7 (tujuh) jam per hari, maka rata-rata 44 persen waktu kerja produktif (169 jam) per tiga bulan, belum digunakan.

4. Berdasarkan pengamatan lapangan, usaha kolam masih dapat lebih diintensifkan sampai batas tertentu terutama jumlah populasi ikan mas dan jumlah pakan yang diberikan. Untuk usaha ternak (kambing), upaya yang dapat dilakukan adalah intensifikasi pemeliharaan guna meningkatkan pendapatan yang signifikan dari biaya yang dikorbankan.

\section{Saran}

1. Solusi yang dapat ditawarkan untrk meningkatkan produktivitas tenaga kerja (secara khusus untuk usaha sampingan ternak) adalah agar pemerintah kota dan/ atau pihak lain dapat memfasilitesi teknologi pemeliharaan ternak yang lebih intensif.

2. Untuk memanfaatkan jam kerja yang masih menganggur, perlu diperkenalkan usaha-usaha produktif selain yang sudah berkembang selama ini. Industri rumah tangga berbahan baku hasil pertanian dan/ atau nonpertanian merupakan salah satu altematif yang dapat dilakukan petani. Tahap awal perlu dilakukan pembekalan petani melalui serangkaian pelatihan dan/ atau pemberdayaan. Hal ini, tentu saja memerlukan kajian lebih lanjut agar kegiatan yang ditawarkan relevan dengan kondisi petani.

\section{DAFTAR PUSTAKA}

Anwar, Affendi. (1997), Organisasi Ekonomi, Konsep Pilihan Aktivitas Ekonomi Melalui Kelembagaan Pasar atau Organisasi, Program Studi IImu Perencanaan Pembangunan Wilayah dan Pedesaan, Program Pascasarjana Institut Pertanian Bogor (Bahan kuliah tidak dipublikasikan).

Becker, Gary S. (1976), The Economic Approach to Human Behavior, Chicago, The University of Chicago Press.

Huntsberger, David V. and Patrick Billingsley. (1973), Element of Statistical Inference, Boston, Allyn and Bacon Inc.

M ubyarto. (1989), Pengantar Ekonomi Pertanian, J akarta, LP3ES. 